CLINICAL STUDY

\title{
A purification step prior to commercial sensitive immunoassay is necessary to achieve clinical usefulness when quantifying serum $17 \beta$-estradiol in prepubertal children
}

\author{
Carina Ankarberg-Lindgren and Ensio Norjavaara \\ Department of Paediatrics, Institute of Clinical Sciences, The Sahlgrenska Academy at Göteborg University, S-416 85, Göteborg, Sweden \\ (Correspondence should be addressed to C Ankarberg-Lindgren; Email: carina.ankarberg-lindgren@vgregion.se)
}

\begin{abstract}
Objective: To test the clinical usefulness of sensitive commercial immunoassays for determination of low $17 \beta$-estradiol concentrations in children.

Methods: The lower limit of detection and clinical usefulness (functional sensitivity) of three commercial estradiol immunoassays were validated by use of 500 sera from prepubertal and pubertal children and 55 pooled sera. The three immunoassays consisted of two modified direct immunoassays; one RIA (Spectria Estradiol RIA) and one time-resolved fluoroimmunoassay (AutoDELFIA Estradiol), both with increased serum volume in relation to antibody concentration and extended incubation time. In the third method, serum was purified and concentrated using diethyl ether extraction prior to measurement by the modified Spectria Estradiol RIA.

Results: The lower limits of detection and clinical usefulness were 9 and $30 \mathrm{pmol} / \mathrm{l}$ for the direct RIA, 11 and $50 \mathrm{pmol} / \mathrm{l}$ for the AutoDELFIA, and 4 and $6 \mathrm{pmol} / \mathrm{l}$ for serum determined by extraction RIA. When measuring the serum pool originating from girls at breast stages $1-2$, the direct RIA and AutoDELFIA resulted in significantly higher $17 \beta$-estradiol concentrations when compared with the extraction RIA $(+58$ and $+267 \%, P<0.001)$. We found a significant difference in $17 \beta$-estradiol concentrations between girls at breast stages 1 (median $6 \mathrm{pmol} / \mathrm{l}$ ) and 2 (median $16 \mathrm{pmol} / \mathrm{l}$ ), when quantified by the extraction RIA $(P<0.0001)$ but no difference when quantified with the direct RIA (median values 12 and $14 \mathrm{pmol} / \mathrm{l}$ respectively).

Conclusion: For determination of low serum $17 \beta$-estradiol concentrations in children, an extraction step prior to commercial immunoassay is needed to achieve clinically useful results.
\end{abstract}

European Journal of Endocrinology 158 117-124

\section{Introduction}

Specific and sensitive assays for $17 \beta$-estradiol measurements are needed in clinical practice for evaluation of pubertal disorders in children and low postmenopausal levels in women, as well as for monitoring aromatase inhibitor therapy and sex replacement hormone therapy in both adults and children.

Measurements of $17 \beta$-estradiol obtained by mass spectrometry identification are considered as the reference method (1-3). However, until mass spectrometry is practical for widespread use, the most widely used technique for the measurement of serum $17 \beta$-estradiol is and will be immunoassays, due to its simplicity and reliability. A trend is to use high-performance automated instruments with use of small specimen volumes. For the most part, these commercial assays are designed for fertility investigations in female adults, but they are not sensitive enough for quantifying the low levels present in children (4), men, and postmenopausal women (3, 5). Despite improvements regarding sensitivity during recent years, direct assays have not been thoroughly validated for low $17 \beta$-estradiol concentrations in serum and have not reached the degree of sensitivity and specificity in clinical practice as expected from the manufacturers' documentation. It has been shown that in samples from postmenopausal women with low $17 \beta$-estradiol, extraction RIAs correlate better with mass spectrometry than direct assays do (3).

In this study, we evaluate two sensitive commercial $17 \beta$-estradiol immunoassays for clinical usefulness in prepubertal and pubertal children. As our standard for comparison, we use an extraction RIA which we have used in our clinical practice for a decade (6).

\section{Materials and methods}

\section{Clinical samples}

All samples used in this study are serum samples submitted for routine clinical testing in children. After 
$17 \beta$-estradiol measurements for routine clinical testing, identification markings were removed from all samples. In the comparison between the direct RIA and extraction RIA, pubertal stages according to Tanner (7) and ages were registered in addition to $17 \beta$-estradiol values.

\section{Assay procedure}

Spectria direct RIA The original assay was a coated tube RIA (Spectria Estradiol RIA, Orion Diagnostica, Espoo, Finland) with lower detection limit $30 \mathrm{pmol} / \mathrm{l}$ (defined as the apparent concentration two S.D. from the counts at maximum binding). The cross-reactivity of the estradiol antiserum had been tested by the manufacture for 30 estradiol-related steroids. The cross-reactivity was below $1 \%$ for estrone, 16-oxestradiol, estradiol-3-glucuronide, estriol, and 16-hydroxy estrone, below $0.1 \%$ for progesterone, corticosterone, 2-hydroxyestradiol, and below $0.001 \%$ for the rest of the related steroids.

To increase the sensitivity of the RIA, $150 \mu \mathrm{l}$ serum was used instead of $100 \mu \mathrm{l}$. The incubation time was extended from $2 \mathrm{~h}$ at $37^{\circ} \mathrm{C}$ to $16-19 \mathrm{~h}$ at room temperature. In addition to the kit calibrators with the lowest concentration of $50 \mathrm{pmol} / \mathrm{l}$, three calibrators of lower concentrations $(6.25,12.5$, and $25 \mathrm{pmol} / \mathrm{l})$ were prepared by dilution of the $50 \mathrm{pmol} / \mathrm{l}$ calibrator with the zero calibrator. Otherwise, the RIA was conducted according to the manufacturer's instructions.

Spectria extraction RIA In the extraction RIA, serum was purified and concentrated using diethyl ether extraction prior to quantifying the $17 \beta$-estradiol concentrations by Spectria. The basic method has been published previously $(6,8)$, although the latest revision has not been published before. In the present study, $4 \mathrm{ml}$ diethyl ether (high performance liquid chromatography grade, Merck 1.00921) was added by a dispenser (Hirschmann Laborgeräte, Eberstadt, Germany) to $450 \mu \mathrm{l}$ serum in $10 \mathrm{ml}$ glass tubes with a tight stopper (rubber, coated with Teflon). For confirmation of the detection limit when the aim was to only purify the serum, $2 \mathrm{ml}$ diethyl ether was added to $200 \mu \mathrm{l}$ serum in $10 \mathrm{ml}$ glass tubes. The sex steroids were extracted to the ether phase for $30 \mathrm{~min}$ in a rotation mixer. The serum phase was thereafter frozen by putting the tubes in a beaker with a mixture of $99.5 \%$ ethanol and dried ice. The ether phase was transferred to $5 \mathrm{ml}$ glass tubes, and totally evaporated on a $37^{\circ} \mathrm{C}$ heat block under a stream of nitrogen. Reconstitution was made using $200 \mu \mathrm{l}$ zero calibrator (Spectria Estradiol zero calibrator, Orion Diagnostica). After incubation at $37^{\circ} \mathrm{C}$ for $20 \mathrm{~min}$ and vortexing, the samples were ready for quantification by the modified Spectria Estradiol RIA, using $150 \mu \mathrm{l}$. The entire extraction procedure was done in duplicate.
To assess recovery of the extraction procedure, serum samples from ten different children were incubated with a small amount of tritiated $17 \beta$-estradiol for $2-3 \mathrm{~h}$ in a shaking water bath $\left(37^{\circ} \mathrm{C}\right)$. The extraction procedure was then performed as above. The radioactivity was determined in $150 \mu \mathrm{l}$ of the final sample volume. The recovery of $17 \beta$-estradiol using the extraction procedure was $91 \pm 1 \%$ (mean \pm s.D.), which was close to the theoretical recovery of $90 \%$. These results are in line with our earlier estimation of the extraction procedure (6). All results have been corrected for the extraction loss.

AutoDELFIA assay The original assay is an automated time-resolved fluoroimmunoassay (AutoDELFIA Estradiol, Wallac oy, Turku, Finland) with a lower detection limit $50 \mathrm{pmol} / \mathrm{l}$, as stated by the manufacturer and Brito et al. (9). Required sample volume is $25 \mu \mathrm{l}$. To increase the sensitivity of the assay, the antibody was diluted 1:18 instead of 1:10 and incubation time was extended to $2 \mathrm{~h}$. In addition to the kit calibrators; with the lowest concentration of $50 \mathrm{pmol} / \mathrm{l}$, one calibrator of lower concentrations $(15 \mathrm{pmol} / \mathrm{l})$ was prepared by dilution with a zero calibrator. Otherwise, the AutoDELFIA was conducted according to the manufacturer's instructions.

\section{Assay evaluation}

Spectria assay To estimate the lower analytical detection limit, replicates of 20 zero calibrators were measured in three different assays of different kit lots. The analytical sensitivity was confirmed in dilution tests in which 100 serum samples from children were purified by the extraction procedure using $200 \mu \mathrm{l}$ serum and $2 \mathrm{ml}$ diethyl ether, and thereafter diluted 1:2 with the zero calibrator from the kit. In addition, two purified serum samples were serially diluted 1:2 with the zero calibrator down to the estimated detection limit.

Assay precision was assessed by use of pooled serum from children and one commercial quality control (Lyphochek from Bio-Rad). Each serum pool was measured as a duplicate in 10-20 different assays of at least four different kit lots. The interassay coefficient of variations (CV) were calculated from the mean of the duplicates. Clinical usefulness (usually termed functional sensitivity) was defined as the lowest concentration of an assay that can be measured with an interassay $\mathrm{CV}$ of $20 \%$.

To assess accuracy, 17 $\beta$-estradiol was removed by charcoal stripping in two different pooled child sera, originating from prepubertal children and children in early puberty. After charcoal stripping, the samples were divided in two, and $24 \mathrm{pmol} / \mathrm{l} 17 \beta$-estradiol was added (spiked) in one of each pair of charcoal stripped child sera. 
Charcoal stripped sera and spiked sera were thereafter measured with direct RIA and extraction RIA.

The concentration of sex hormone-binding globulin (SHBG) in the zero calibrator was determined in four different zero calibrator lots by RIA (Orion Diagnostica).

To test the clinical reliability of the extraction RIA, all $17 \beta$-estradiol results during the years 2004-2006 originated from girls with precocious puberty undergoing long-acting gonadotrophin-releasing hormone (GnRH) analog treatment. The goal of the treatment was to reversibly stop pubertal development by suppressing gonadotropins/ $17 \beta$-estradiol levels to the prepubertal range.

The AutoDELFIA assay The minimal detection concentration for the modified sensitive AutoDELFIA was calculated with the aid of a precision profile, defined as the lowest level that could be measured with an intraassay $\mathrm{CV}$ of $10 \%$. Assay precision was tested in four child serum pools: girls breast stages 1-2, girls breast stage 2, girls breast stages 2-4 (7), and one commercial control.

\section{Comparison between extraction RIA and direct immunoassays}

To evaluate the concordance between the direct immunoassays and the established extraction RIA, 275 serum samples were run in parallel with the direct RIA and the extraction RIA. The serum samples originated from 229 females aged 0-19 years (median 11 years) at pubertal stages $1-5$ and 46 pooled child sera. In addition, 122 children's serum samples were run in parallel with the AutoDELFIA and the extraction RIA.

\section{Statistical analysis}

Linear regression analyses were performed on logtransformed data. Method comparison was evaluated by a Bland-Altman plot (10). Undetectable values, i.e., values below zero, were set to $1 \mathrm{pmol} / \mathrm{l}$. A value of $P<0.05$ was considered significant (11).

\section{Results}

\section{Assay validations}

The modified Spectria's analytical detection limit was $9 \mathrm{pmol} / \mathrm{l}$, calculated as the apparent concentration 3s.D. from the counts at maximum binding. The analytical detection limit was confirmed in dilution tests, in which purified, not concentrated, serum samples from children could be diluted down to $9 \mathrm{pmol} / \mathrm{l}$ and obtain expected $17 \beta$-estradiol concentrations (Fig. 1A). The purified samples showed linearity down to the detection limit of $9 \mathrm{pmol} / \mathrm{l}$ and even lower concentrations (Fig. 1B). An analytical detection limit of $9 \mathrm{pmol} / \mathrm{l}$ is equal to $4 \mathrm{pmol} / \mathrm{l}$ $(1.2 \mathrm{pg} / \mathrm{ml})$ for serum samples that have been concentrated in the diethyl ether extraction step prior to quantification by Spectria Estradiol RIA.

The minimal detection concentration for the modified sensitive AutoDELFIA was estimated to be $11 \mathrm{pmol} / \mathrm{l}$ by the automated instrument.

The results of imprecision studies conducted with child serum pools are summarized in Table 1 . The serum pool originating from girls at breast stages 1-2,
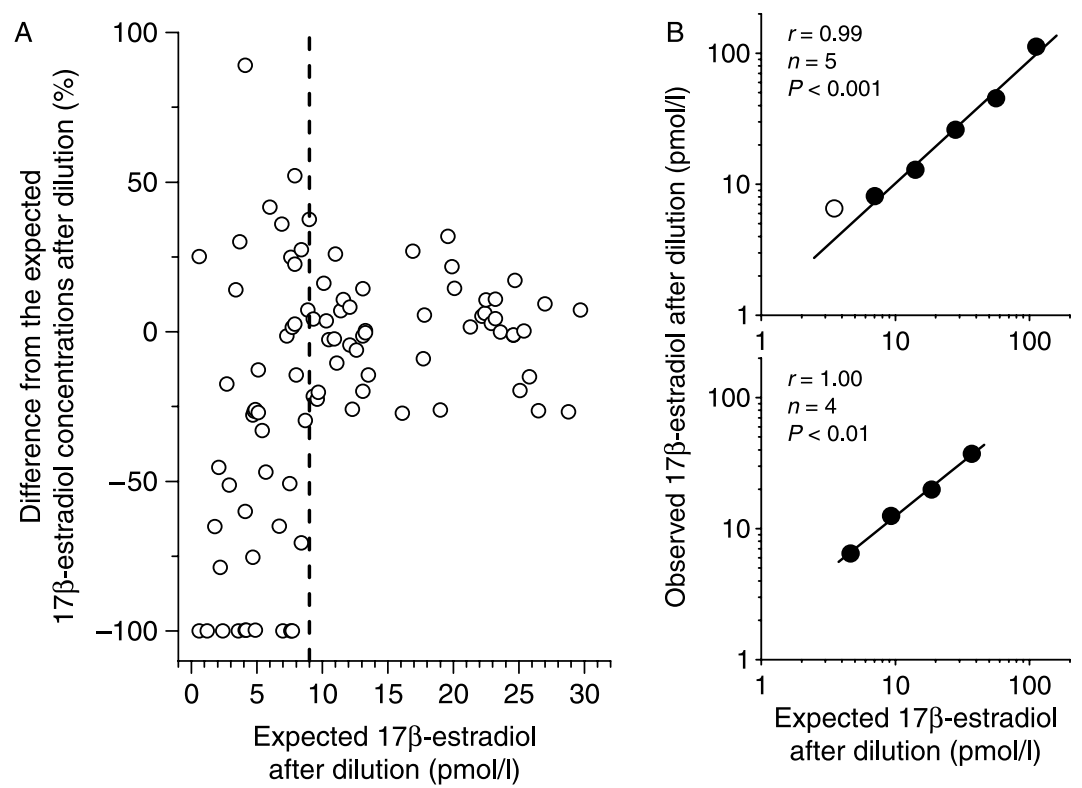

Figure 1 Confirmation of the analytical detection limit for the modified $17 \beta$-estradiol RIA by dilution tests. (A) One hundred child serum samples were purified from potentially interfering substances by the diethyl ether extraction step. Each of these was diluted 1:2 using zero calibrator from the Spectria Estradiol kit. Undiluted and diluted serum samples were measured in duplicate by the modified RIA. Serum $17 \beta$-estradiol concentrations could be diluted down to $9 \mathrm{pmol} / \mathrm{l}$ (the estimated lower limit of detection for the RIA) and provide an adequate reading. (B) Linear regression analyses between expected and observed $17 \beta$-estradiol concentrations after serial dilution in two samples where the steroids had been purified by diethyl ether extraction and thereafter reconstituted in zero calibrator before serial dilution, maintaining a constant SHBG concentration. Linear regression analyses are calculated on the filled symbols. 


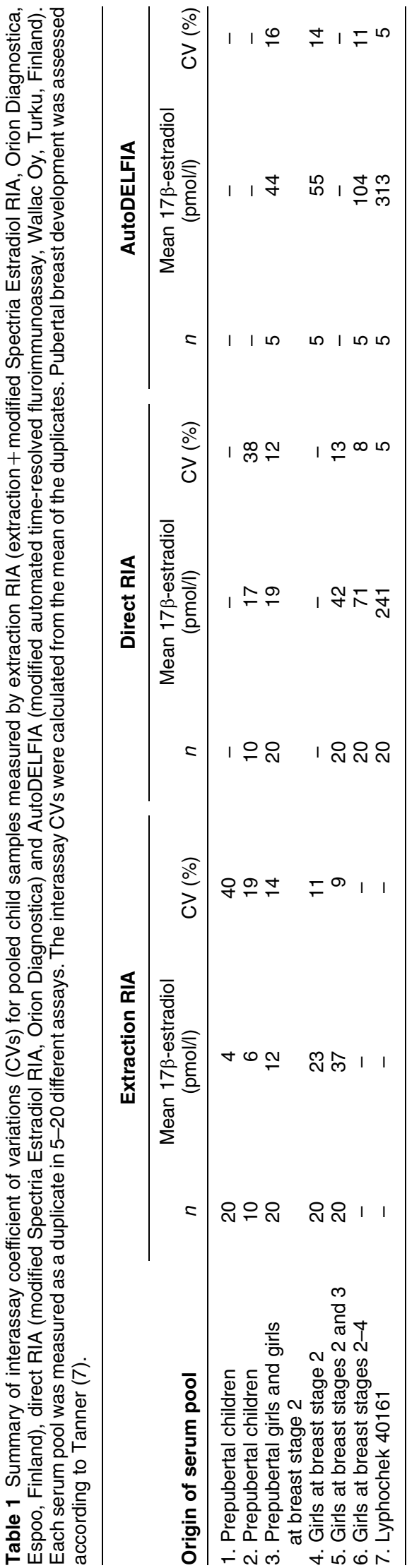

resulted in significantly higher $17 \beta$-estradiol concentrations when measured by the direct RIA and AutoDELFIA when compared with measurements by the extraction Spectria $(n=20, P<0.001,+58 \%$ and $n=5, P<0.001,+267 \%$ respectively).

Charcoal stripping of child sera resulted in mean $17 \beta$-estradiol concentration below the detection limit $(<4 \mathrm{pmol} / \mathrm{l})$ when determined by extraction RIA but resulted in a mean value of $15 \mathrm{pmol} / \mathrm{l}$ when determined by direct RIA. The corresponding spiked sera resulted in concentration of $22 \mathrm{pmol} / \mathrm{l}$ when determined by extraction RIA and $35 \mathrm{pmol} / \mathrm{l}$ when determined by direct RIA. The expected concentration in the spiked sera was $24 \mathrm{pmol} / \mathrm{l}$.

Our laboratory participates in the Bio-Rad External Quality Assurance Services. For the year 2006, the direct $17 \beta$-estradiol RIA's and the extraction $17 \beta$-estradiol RIA's bias from the mean of 125 laboratory results were -24 and $-26 \%$ respectively.

The SHBG concentrations in the zero calibrators range between 10 and $26 \mathrm{nmol} / \mathrm{l}$ (median $25 \mathrm{nmol} / \mathrm{l}$ ).

\section{Clinical usefulness}

The functional sensitivity of the concentration where the interassay $\mathrm{CV}$ is $20 \%$ is estimated at $6 \mathrm{pmol} / \mathrm{l}$ $(1.6 \mathrm{pg} / \mathrm{ml})$ for the extraction RIA (Table 1). The $17 \beta$-estradiol concentrations quantified with the extraction RIA in samples from girls (aged 4-17 years) during prepuberty (with Tanner breast stage $1 ; n=47$ ) and early puberty (Tanner breast stage 2 ; $n=54$ ) ranged between $<4-25$ and $5-88 \mathrm{pmol} / \mathrm{l}$, with median values 6 and $16 \mathrm{pmol} / \mathrm{l}$ respectively. The corresponding values for the direct RIA was $<9-46$ and $<9-70 \mathrm{pmol} / \mathrm{l}$, with median values 12 and 14 respectively. We found a significant difference in $17 \beta$ estradiol concentrations between girls with breast stages 1 (prepubertal) and 2 (early puberty), when quantified by the extraction RIA $(P<0.0001)$ but no difference when quantified with the direct RIA. Samples from girls with breast stage 1, measured by the direct RIA, were significantly higher than those measured by the extraction RIA $(P<0.01)$.

The clinical reliability of the extraction RIA is demonstrated in Fig. 2. In total, 37 serum samples from girls with precocious puberty had been quantified for $17 \beta$-estradiol measurements at our laboratory. Seven of these samples were submitted due to clinical suspicion of lack of treatment efficacy (pubertal progress). All these samples resulted in $17 \beta$-estradiol concentrations in the pubertal range. Thirty samples were sent as a routine control. Out of 30 cases, 24 resulted in levels seen during prepuberty.

The functional sensitivity of the concentration where the interassay $\mathrm{CV}$ is $20 \%$ is estimated to be between 17 and $42 \mathrm{pmol} / \mathrm{l}$ for the direct RIA (Table 1). The results from the relationship between samples purified and concentrated by extraction with diethyl ether prior to 


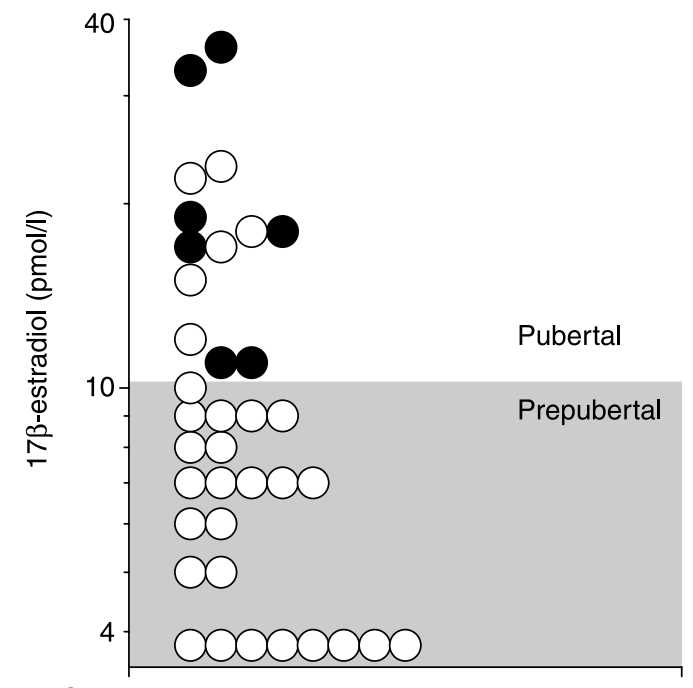

Figure 2 Serum 17 $\beta$-estradiol concentrations in girls with precocious puberty during long-acting $\mathrm{GnRH}$ analog treatment when compared with spontaneous $17 \beta$-estradiol secretions in healthy prepubertal girls. The gray area represents peak value of $17 \beta$-estradiol levels seen in healthy prepubertal girls. During the years 2004-2006, in total 37 samples were analyzed for therapy check-up during longacting $\mathrm{GnRH}$ analog treatment. In seven cases, the reason for sending the samples was clinical suspicion of lack of treatment efficacy (filled circles), suspected to have $17 \beta$-estradiol in the pubertal range and in the other 30 cases there was no more information than 'check-up of treatment' (open circles).

measurement by RIA and samples quantified directly by RIA are shown in Fig. 3. We found a close correlation for $17 \beta$-estradiol concentrations down to the estimated analytical detection limit for the Spectria, $9 \mathrm{pmol} / \mathrm{l}$ $(r=0.93, \quad P<0.0001, \quad n=219, \quad Y=0.95 X+1.78$, Fig. 3A). However, below $30 \mathrm{pmol} / \mathrm{l}$, the discrepancy between the two methods is far above $20 \%$ (Fig. 3B). The results for the linear regression analysis of $17 \beta$-estradiol concentrations, above $30 \mathrm{pmol} / \mathrm{l}$, were: $r=0.97$, $P<0.0001, n=94, Y=0.97 X-0.92$. Therefore, we establish the clinical usefulness to be $30 \mathrm{pmol} / \mathrm{l}$ for the direct RIA.

The functional sensitivity of the concentration where the interassay CV is $20 \%$ is estimated to be below $44 \mathrm{pmol} / \mathrm{l}$ for the AutoDELFIA (Table 1). The results from the relationship between samples quantified directly by AutoDELFIA and samples quantified by the extraction RIA are shown in Fig. 4. We found a close correlation for $17 \beta$-estradiol concentrations between the two assays $(r=0.92, \quad P<0.0001, n=108$, $Y=0.98 X+17.5$, Fig. 4A) for values above the analytical detection limits. However, below $50 \mathrm{pmol} / \mathrm{l}$, the discrepancy between the two methods was far above $20 \%$ (Fig. 4B). Therefore, we establish the clinical usefulness to be $50 \mathrm{pmol} / \mathrm{l}$ for the AutoDELFIA. The AutoDELFIA method's difference from the mean value of extraction RIA and AutoDELFIA resulted in 20\% higher $17 \beta$-estradiol concentrations (Fig. 4B).

\section{Discussion}

We present three $17 \beta$-estradiol immunoassays with low analytical detection limits (4, 9, and $11 \mathrm{pmol} / \mathrm{l})$. However, only the extraction RIA obtained a functional sensitivity close to the analytical sensitivity. In addition, the extraction RIA manages to distinguish prepubertal values from early pubertal values. While the extraction RIA gives clinically useful results down to $6 \mathrm{pmol} / \mathrm{l}$, the direct immunoassays could only perform clinically useful results down to 30-50 pmol/l.

Previously published papers have shown the importance of using an extraction step prior to immunoassay for determination of the low serum concentration present in postmenopausal women $(3,5)$. In our study, we show the importance of a preceding purification and concentration of the analyte prior to quantification by commercial RIA for determination of low serum $17 \beta$-estradiol concentrations in children. Together, these studies establish that direct immunoassays do not perform well at low $17 \beta$-estradiol concentrations, not even those with low analytical detection limit. This may be due to potentially interfering substances, particularly cross-reacting water-soluble steroid conjugates, binding proteins (especially SHBG), and non-specific binding (NSB). Concentrations of SHBG are known to be high in prepubertal children (median $92 \mathrm{nmol} / \mathrm{l})(12,13)$ and postmenopausal women (mean $103 \mathrm{nmol} / \mathrm{l}$ ) (14), and in combination with the 5000-15 000 times lower $17 \beta$-estradiol concentrations it is a challenge to quantify accurate concentrations of $17 \beta$-estradiol. In this study, we show that the $17 \beta$-estradiol calibrators included in the Spectria kit on average contain four times lower SHBG concentrations when compared with that in children's sera. To obtain accurate results with a direct immunoassay, the concentration of SHBG, and NSB in a patient's serum samples ought to be similar to that in the calibrators (15-17). Using an extraction step prior to quantification by RIA, the patient's SHBG and NSB are replaced by a zero calibrator containing the same concentration of SHBG and NSB as is found in the calibrators in the kit. However, if the assay has problems with high cross-reactivity, an extraction does not overcome these problems. The Spectria assay that we use has very low cross-reactivity with estradiol-related steroids.

By charcoal stripping, it was confirmed that the interfering substances present in child sera are removed by the ether extraction procedure. Charcoal stripping removes $99 \%$ of initially present estradiol (18) and is a common procedure when producing zero calibrators. In this study, the expected $17 \beta$-estradiol concentration after charcoal stripping was $0 \mathrm{pmol} / \mathrm{l}$ and after spiking, the expected $17 \beta$-estradiol concentration was $24 \mathrm{pmol} / \mathrm{l}$. The extraction RIA resulted in correct $17 \beta$-estradiol concentrations, both before and after spiking, but the direct RIA 

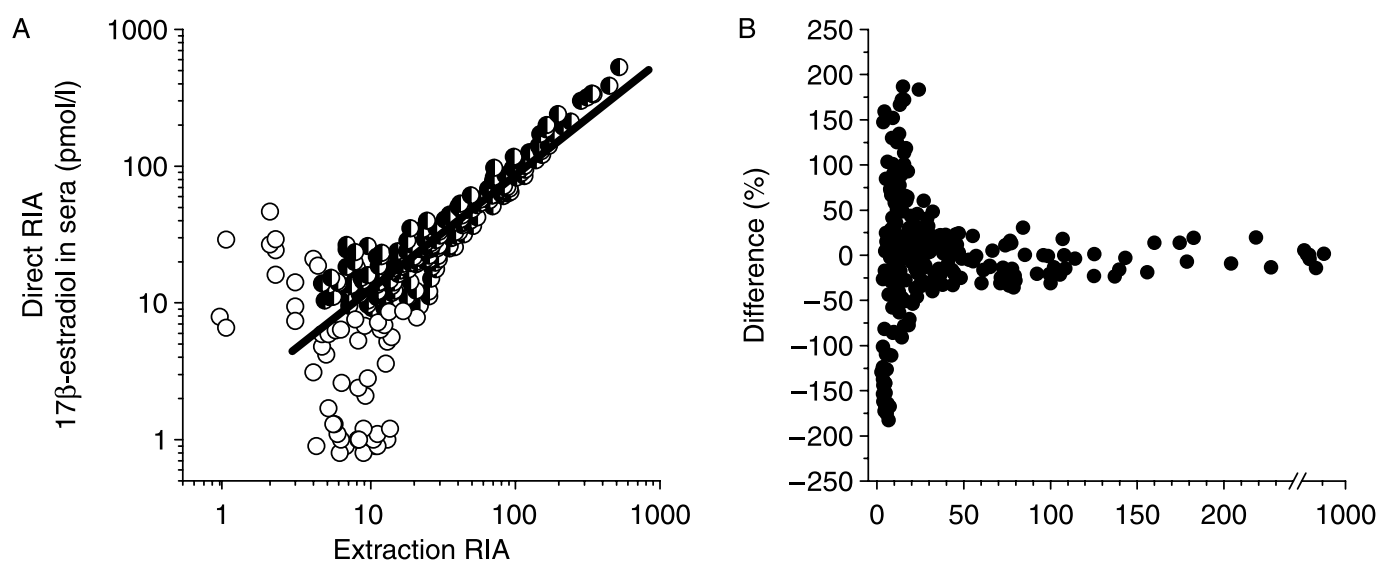

$17 \beta$-estradiol in purified samples ( $\mathrm{pmol} / \mathrm{l})$

Mean direct RIA and extraction RIA (pmol/I)

Figure 3 Assay comparison between the extraction RIA and the direct RIA. (A) Correlation in 17 $\beta$-estradiol concentrations between samples that have been purified by extraction of diethyl ether preceding RIA and serum quantified directly by RIA $(n=275)$. Linear regression analysis (filled symbols) excludes values below the detection limits $(r=0.93, n=219, P<0.0001)$. (B) Bland-Altman plot of the difference in 17 $\beta$-estradiol concentrations (serum quantified directly in the RIA minus samples that have been extracted by diethyl ether preceding RIA expressed as a percentage of the mean) against the mean of direct RIA and extraction RIA.
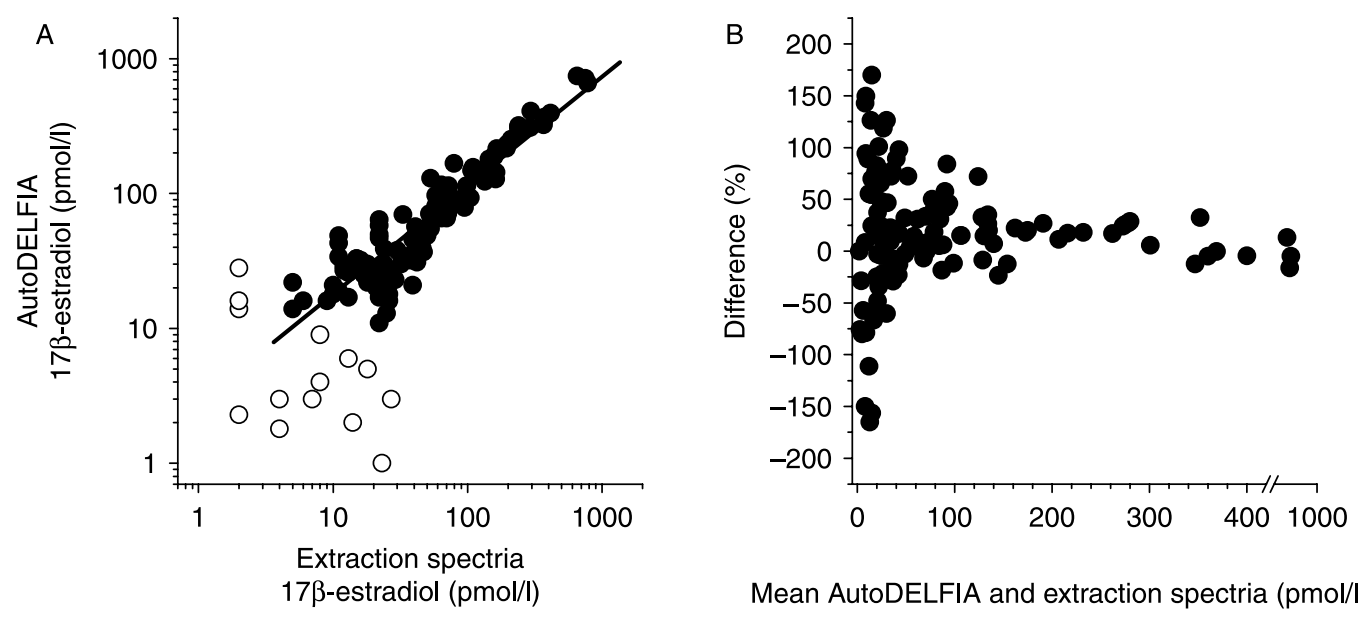

Mean AutoDELFIA and extraction spectria (pmol/l)

Figure 4 Assay comparison between the extraction RIA and direct AutoDELFIA. (A) Correlation in 17 $\beta$-estradiol concentrations between samples that have been purified by extraction of diethyl ether preceding RIA and serum quantified directly by AutoDELFIA ( $n=122)$. Linear regression analysis (filled symbols) excludes values below the detection limits $(r=0.92, n=108, P<0.0001)$. (B) Bland-Altman plot of the difference in 17 $\beta$-estradiol concentrations (serum quantified by AutoDELFIA minus samples quantified by extraction RIA expressed as a percentage of the mean) against the mean of AutoDELFIA and extraction RIA.

resulted in falsely high concentrations both after charcoal stripping and after addition of known amounts of $17 \beta$ estradiol.

The overestimation of $17 \beta$-estradiol concentrations in the direct immunoassays was also demonstrated by the impression data. The pooled serum samples originating from prepubertal girls and girls at breast stage 2 generally resulted in an overestimation. It is typical that the serum pools numbered 2 and 3 resulted in similar mean $17 \beta-$ estradiol concentrations when measured by the direct RIA, but the serum pool originating from prepubertal children resulted in a much higher interassay CV than the serum pool originating from both prepubertal and pubertal girls. The results obtained by the AutoDELFIA are still overestimating and are similar to those obtained by the original method (9).

By directly or indirectly increasing the sample volumes and incubation times, we decreased the analytical detection limits from 30 and $50 \mathrm{pmol} / \mathrm{l}$ down to 9 and $11 \mathrm{pmol} / \mathrm{l}$ respectively, but we did not improve the clinical usefulness. The analytical sensitivity is estimated by determining the imprecision of the zero calibrator, which does not always correspond to the detection limit in the intended specimen. This is because the specimens are less pure and may contain interfering substances. In this study, purification by diethyl ether extraction of the children's serum samples was required to confirm the analytical sensitivity. 
The most sensitive assays are considered to be the recombinant cell bioassays (RCBA). Klein and coworkers have developed a RCBA to measure estrogenic activity with a detection limit between 0.07 and $0.7 \mathrm{pmol} / \mathrm{l} 17 \beta$-estradiol equivalents. The sample volume used was $800 \mu \mathrm{l}$, the interassay CV was $13 \%$ at $7 \mathrm{pmol} / \mathrm{l}$ and increased to about $60 \%$ at $0.07 \mathrm{pmol} / \mathrm{l}$ $(19,20)$. Another RCBA has been developed by Paris et al. (21). The required sample volume is $800 \mu \mathrm{l}$ and the detection limit is below $4 \mathrm{pmol} / \mathrm{l}$. The interassay $\mathrm{CV}$ was $20 \%$ at $6 \mathrm{pmol} / \mathrm{l}$. It has been shown previously that RCBA correlates to gas chromatography-tandem mass spectrometry (22). The extraction RIA corresponds well with RCBA for values down to the analytical limits (23). Furthermore, the $17 \beta$-estradiol values obtained in prepubertal girls with our extraction RIA are more or less identical to those obtained by $\operatorname{RCBA}(20,21)$. By compilation of all this data, we estimate that our modified commercial extraction RIA has similar clinical usefulness as RCBAs.

There are three clinical situations in pediatrics where there is a need to determine low $17 \beta$-estradiol levels in girls to: 1) establish whether puberty has started, 2) monitor GnRH (lutenizing hormone releasing hormone) analog treatment of precocious puberty and 3) monitor hormone replacement therapy in hypogonadal children. The extraction RIA has the sensitivity to establish whether puberty has started or not and to determine the low $17 \beta$-estradiol levels seen at pubertal induction with transdermal estradiol patches in hypogonadal girls $(6,8)$. Figure 2 shows the results from 37 samples sent to our laboratory during the years 2004-2006 for therapy control of treatment of precocious puberty with long-acting GnRH analog. The goal of the treatment is to reversibly stop pubertal development, by suppressing gonadotropins/17 $\beta$-estradiol levels to the prepubertal range (24). The state of the art method is to show that the efficacy of the treatment has been accomplished by GnRH challenge test. However, development of sensitive methods for determining $17 \beta$-estradiol makes it possible to assess the efficacy of the treatment more simply and inexpensively by determination of $17 \beta$-estradiol instead of gonadotropins after GnRH test (25). Some pediatricians have used this possibility and sent samples to our laboratory for analysis. In all seven cases where the reason for analysis was clinical suspicion of lack of efficacy, all the samples had pubertal levels. In 24 out of 30 cases where there was no information about the efficacy, serum $17 \beta$-estradiol concentrations were in the prepubertal range or under the detection limit of the assay. Even if the result is further confounded by not knowing the reasons for therapy control, the result lends further support to the theory that the assay works for use in a clinical setting. The extraction RIA is at present an accredited assay by SWEDAC in Sweden, SS-EN ISO 15189 (no. 1899).

In conclusion, commercially sensitive immunoassays do not give clinically useful results in sera from prepubertal children and children in early puberty. A purification step prior to commercially sensitive immunoassay is necessary to achieve clinically useful results when quantifying serum 17ß-estradiol in children. Clinical laboratories should be aware that the clinical usefulness of their current procedures may be far from the method's analytical detection limit. It is important to validate each assay for its intended purpose.

\section{Acknowledgements}

The authors wish to thank Ann-Marie Månqvist at Tillväxtlaboratoriet for the technical support and Kerstin Albertsson Wikland for a place of work with excellent facilities. This work was supported by grants from The Sahlgrenska Academy at Göteborg University, the Swedish Medical Research Council (No. 7509), The Petter Silfverskiöld foundation and an unrestricted research grant from Pfizer AB.

\section{References}

1 Nelson RE, Grebe SK, DJ OK \& Singh RJ. Liquid chromatographytandem mass spectrometry assay for simultaneous measurement of estradiol and estrone in human plasma. Clinical Chemistry 2004 50 373-384.

2 Tai SS \& Welch MJ. Development and evaluation of a reference measurement procedure for the determination of estradiol17 beta in human serum using isotope-dilution liquid chromatography-tandem mass spectrometry. Analytical Chemistry $2005776359-6363$.

3 Lee JS, Ettinger B, Stanczyk FZ, Vittinghoff E, Hanes V, Cauley J, Chandler W, Settlage J, Beattie M, Folkerd E, Dowsett M, Grady D \& Cummings SR. Comparison of Methods to Measure Low Serum Estradiol Levels in Postmenopausal Women. Journal of Clinical Endocrinology and Metabolism 200691 3791-3797.

4 Bay K, Andersson AM \& Skakkebaek NE. Estradiol levels in prepubertal boys and girls - analytical challenges. International Journal of Andrology 200427 266-273.

5 Stanczyk FZ, Cho MM, Endres DB, Morrison JL, Patel S \& Paulson RJ. Limitations of direct estradiol and testosterone immunoassay kits. Steroids 200368 1173-1178.

6 Norjavaara E, Ankarberg C \& Albertsson-Wikland K. Diurnal rhythm of 17 beta-estradiol secretion throughout pubertal development in healthy girls: evaluation by a sensitive radioimmunoassay. Journal of Clinical Endocrinology and Metabolism $1996814095-4102$.

7 Tanner JM. Growth at Adolescence Oxford: Blackwell Scientific publication, 1962 .

8 Ankarberg-Lindgren C, Elfving M, Wikland KA \& Norjavaara E. Nocturnal application of transdermal estradiol patches produces levels of estradiol that mimic those seen at the onset of spontaneous puberty in girls. Journal of Clinical Endocrinology and Metabolism 200186 3039-3044.

9 Brito VN, Batista MC, Borges MF, Latronico AC, Kohek MB, Thirone AC, Jorge BH, Arnhold IJ \& Mendonca BB. Diagnostic value of fluorometric assays in the evaluation of precocious puberty. Journal of Clinical Endocrinology and Metabolism $1999 \mathbf{8 4}$ 3539-3544.

10 Bland JM \& Altman DG. Comparing methods of measurement: why plotting difference against standard method is misleading. Lancet 1995346 1085-1087. 
11 Altman DG. Practical Statistics for Medical Research London: Chapman and Hall, 1991.

12 Ankarberg C \& Norjavaara E. Diurnal rhythm of testosterone secretion before and throughout puberty in healthy girls: correlation with 17beta-estradiol and dehydroepiandrosterone sulfate. Journal of Clinical Endocrinology and Metabolism $1999 \mathbf{8 4}$ 975-984.

13 Ankarberg-Lindgren C \& Norjavaara E. Changes of diurnal rhythm and levels of total and free testosterone secretion from pre to late puberty in boys: testis size of $3 \mathrm{ml}$ is a transition stage to puberty. European Journal of Endocrinology 2004151 747-757.

14 Adly L, Hill D, Sherman ME, Sturgeon SR, Fears T, Mies C, Ziegler RG, Hoover RN \& Schairer C. Serum concentrations of estrogens, sex hormone-binding globulin, and androgens and risk of breast cancer in postmenopausal women. International Journal of Cancer 2006119 2402-2407.

15 Masters AM \& Hahnel R. Investigation of sex-hormone binding globulin interference in direct radioimmunoassays for testosterone and estradiol. Clinical Chemistry 198935 979-984.

16 Slaats EH, Kennedy JC \& Kruijswijk H. Interference of sexhormone binding globulin in the 'Coat-A-Count' testosterone no-extraction radioimmunoassay. Clinical Chemistry 198733 300-302.

17 Carlström K. Low endogenous estrogen levels - analytical problems and tissue sensitivity. Acta Obstetricia et Gynecologica Scandinavica. Supplement 1996163 11-15.

18 Heringa MB, van der Burg B, van Eijkeren JC \& Hermens JL. Xenoestrogenicity in in vitro assays is not caused by displacement of endogenous estradiol from serum proteins. Toxicological Sciences 200482 154-163.

19 Klein KO, Baron J, Colli MJ, McDonnell DP \& Cutler GB, Jr. Estrogen levels in childhood determined by an ultrasensitive recombinant cell bioassay. Journal of Clinical Investigation 199494 2475-2480.
20 Janfaza M, Sherman TI, Larmore KA, Brown-Dawson J \& Klein KO. Estradiol levels and secretory dynamics in normal girls and boys as determined by an ultrasensitive bioassay: a 10 year experience. Journal of Pediatric Endocrinology and Metabolism 200619 901-909.

21 Paris F, Servant N, Terouanne B, Balaguer P, Nicolas JC \& Sultan C. A new recombinant cell bioassay for ultrasensitive determination of serum estrogenic bioactivity in children. Journal of Clinical Endocrinology and Metabolism 200287 791-797.

22 Wang S, Paris F, Sultan CS, Song RX, Demers LM, Sundaram B, Settlage J, Ohorodnik S \& Santen RJ. Recombinant cell ultrasensitive bioassay for measurement of estrogens in postmenopausal women. Journal of Clinical Endocrinology and Metabolism 200590 1407-1413.

23 Ankarberg Lindgren C. Testosterone and 17beta-oestradiol secretion in children and adolescents - assay development, levels for comparison and clinical applications. In $\mathrm{PhD}$ thesis at Department of Pediatrics. Göteborg: Göteborg University, 2005.

24 Grumbach MM \& Styne DM. Puberty: Ontogeny, neuroendocrinology, physiology and disorders. In Williams Textbook of Endocrinology, edn 10th, pp 1115-1286. Eds HM Kronenberg, PR Larsen, S Melmed \& KS Polonsky, Philadelphia, Pennsylvania: Saunders, 2003.

25 Klein KO, Baron J, Barnes KM, Pescovitz OH \& Cutler GB, Jr. Use of an ultrasensitive recombinant cell bioassay to determine estrogen levels in girls with precocious puberty treated with a luteinizing hormone-releasing hormone agonist. Journal of Clinical Endocrinology and Metabolism $1998 \mathbf{8 3} 2387-2389$.

Received 15 October 2007

Accepted 16 October 2007 